Article

\title{
Optimal Management of the Energy Flows of Interconnected Residential Users
}

\author{
Lucrezia Manservigi, Mattia Cattozzo, Pier Ruggero Spina, Mauro Venturini * \\ and Hilal Bahlawan
}

Dipartimento di Ingegneria, Università degli Studi di Ferrara, 44122 Ferrara, Italy; lucrezia.manservigi@unife.it (L.M.); mattia.cattozzo@student.unife.it (M.C.); pier.ruggero.spina@unife.it (P.R.S.); hilal.bahlawan@unife.it (H.B.)

* Correspondence: mauro.venturini@unife.it; Tel.: +39-0532-974878

Received: 6 February 2020; Accepted: 19 March 2020; Published: 22 March 2020

\begin{abstract}
In recent years, residential users have begun to be equipped with micro-CHP (combined heat and power) generation technologies with the aim of decreasing primary energy consumption and reducing environmental impact. In these systems, the prime mover supplies both thermal and electrical energy, and an auxiliary boiler and the national electrical grid are employed as supplementary systems. In this paper, a simulation model, which accounts for component efficiency and energy balance, was developed to replicate the interaction between the users and the energy systems in order to minimize primary energy consumption. The simulation model identified the optimal operation strategy of two residential users by investigating different energy system configurations by means of a dynamic programming algorithm. The reference scenario was compared to three different scenarios by considering independent energy systems, shared thermal and electrical energy storage and also the shared prime mover. Such a comparison allowed the identification of the most suitable energy system configuration and optimized operation strategy. The results demonstrate that the optimized operation strategy smoothes the influence of the size of thermal and electrical energy storage. Moreover, the saving of primary energy consumption can be as high as $5.1 \%$. The analysis of the economic feasibility reveals that the investment cost of the prime mover can be as high as $4000 € / \mathrm{kW}$.
\end{abstract}

Keywords: micro-CHP; residential user; optimization; dynamic programming

\section{Introduction}

\subsection{Problem Statement}

In recent years, several studies have focused on alternative energy production systems with the aim of reducing emissions and primary energy consumption with a target of $20 \%$ in the EU by 2020 [1], thus tackling climate change based on the 2030 Agenda for Sustainable Development [2] and the EU climate and energy framework [3]. One option to achieve these goals envisions that sustainable energy policies are implemented by rationalizing the use of energy resources [4]. The exploitation of district energy systems and smart grids also contributes to this goal.

District energy systems allow heating and cooling demand to be fulfilled [5]. In this case, the energy system is defined and/or designed for process decentralization, allowing improvements in energy efficiency by reducing carbon employment and enhancing renewable resource exploitation [6]. As stated by De Pascali and Bagaini, combined heat and power (CHP) systems represent a suitable technology that can be embedded in a district energy system; in fact, this technology can make district energy systems independent of centralized power grids [7]. In addition, onsite electricity can be 
provided by reducing transmission losses. Finally, waste heat can also be exploited locally [8] and pollutant emissions significantly reduced by means of flue gas treatments [9].

Unlike district energy systems, smart grids are mainly aimed at efficiently providing electricity from the sources to the end-user [10]. In the literature, different smart grid definitions exist, as discussed, for instance, in [11,12]. In general, a smart grid represents every practice or technology that can provide economic and environmental improvement to the power grid [12]. In a smart grid, energy users, called "prosumers," can produce, consume, store or share energy with other users and the national grid.

The smart grid concept can be implemented in several ways, but, according to Ferrari et al. [12], the adoption of CHP units is one of the most promising solutions. In fact, thanks to their economic and functional advantages, CHP systems represent an attractive alternative to the separated production of heat and electricity, proving to successfully meet energy demands for both the industrial sector and residential buildings. Moreover, the study [13] clearly demonstrates that the local environmental impact of the CHP production can be significantly reduced compared to the separated production.

\subsection{Literature Review}

In the literature, $\mathrm{CHP}$ systems are described as having already been widely employed in industrial scenarios, while the residential sector presents a high penetration potential [14-17]. In fact, currently, most residential users still employ a domestic boiler and the national grid to meet their thermal and electrical energy demand, respectively. As stated in [18], building heating accounts for $40 \%$ of total energy consumption [19]. Thus, CHP units are a potential alternative to enhance primary energy savings in residential applications [20]. In the "CHP scenario," a prime mover (PM) supplies both thermal and electrical energy. Some micro-CHP systems for residential building applications are examined in $[1,4,14,21-23]$ by also considering their economic performance.

Energy management systems (EMSs) are fundamental in order to solve energy management problems [24]. In the last few years, several EMS approaches were investigated. For example, Shayeghi et al. [25] classified EMSs as (i) nonrenewable based, (ii) energy storage system based, (iii) demand-side management based and (iv) hybrid system based. Instead, Dehghanpour et al. [26] identified three different categories, namely centralized, distributed and hybrid control. Finally, Ghiani et al. [27] classified EMSs into (i) classical and exact, (ii) heuristic and metaheuristic and (iii) artificial intelligent solution. An indepth analysis was provided by Georgilakis [28]. The exploitation of EMSs has been the object of several research activities. For example, an artificial neural network provided encouraging results in [29] by significantly reducing the primary energy consumption, emissions and operating costs of a microgeneration system coupled with renewable energy. A similar energy system and objective function were optimized by Roy et al. in [30]. Artificial neural network effectiveness was also shown by Seo et al. [31]. Instead, Wang et al. [32] and Wu et al. [33] exploited particle swarm algorithms to optimize the capacity of hybrid energy storage systems.

In [34-38], the optimization procedure was performed by means of a mixed-integer and linear programming strategy (MILP). In particular, the papers [34,35] addressed the optimization of a domestic micro-cogeneration system and a cogeneration power plant, respectively, while distributed energy resources were optimized in [36] to minimize energy costs. Instead, Steen et al. [37] applied the MILP approach to evaluate the feasibility of combining a thermal energy storage (TES) system with distributed energy resources. Wouters et al. [38] employed a MILP model to evaluate the integration of distributed generation units and microgrids in the current grid infrastructure and identify its optimal design. The latest updates about EMSs are documented in [39-41]. In particular, Ford et al. [39] highlighted that there is a lack of understanding of how users interact. Rafique et al. [40] identified the optimal scheduling of electrical and gas energy resources for a smart home by using a genetic algorithm. Sanguinetti et al. [41] investigated the energy benefits related to smart home technology. Instead, Allegrini et al. [42] reviewed the tools that address district-level energy systems by focusing on district-level interactions. 
Dynamic programming (DP) [43] is an optimization strategy that provides the global minimum of a given objective function. According to Yu et al. [44], DP is more effective than linear and nonlinear programming and proves its effectiveness by solving multiple objective function problems by dividing the complex problem into interrelated subproblems [44,45]. In addition, Chen et al. [46] stated that the lack of empirical coefficients and predetermined parameters constitute one of the main advantages in using DP. Nevertheless, DP may require higher computational time than linear algorithms [47], especially if the number of variables increases [46]. Thus, DP may not be suitable for online applications.

In the energy system area, several studies [46,48-50] proved the effectiveness of DP also for residential user applications. In [46], DP was applied to a biofuel micro-CHP system supplied with battery banks and supercapacitors, in order to identify the optimal power distribution for CHP suppliers. The study [48] also validated DP by selecting the optimal control strategy for minimizing primary energy consumption. Furthermore, DP was used in [49] to investigate the dispatch problem by considering a micro-CHP system based on a gas turbine. The DP algorithm was used in [50] to identify the operating logic that allowed cost minimization of a system, including an internal combustion engine, a boiler and a water tank with a resistor. Recently, Bahlawan et al. [51] exploited the DP algorithm in order to optimize both the sizing and operation of hybrid energy plants, with the goal of minimizing primary energy consumption.

\subsection{Objective and Novelty of This Paper}

This paper aims at merging the main achievements of the studies currently available in the literature in this area by combining two novel features, i.e., i) the presence of an energy grid that connects two residential users (the energy grid is considered "smart" since it is assumed bidirectional and perfectly controlled and metered) and ii) the optimization of the management strategy for different energy system configurations and component size, in order to minimize primary energy consumption.

Compared to other studies available in the literature, different perspectives make this paper unique. In fact, the DP algorithm is employed to identify the optimal operating strategy. Thus, the auxiliary boiler $(\mathrm{AB})$ and the national electrical grid are always available to the users. Moreover, different sizes of both the TES and electrical energy storage (EES) are considered and the influence of the district heating grid (DHG) is analyzed. Finally, with respect to a previous study carried out by the same authors in [52], a higher number of energy system configurations are evaluated and the case study, which includes two residential users, is different. In addition, the current paper comprises and discusses the operating strategy of the optimal energy system configuration identified by the DP algorithm.

Thus, the results reported in this paper can be used to evaluate the profitability of micro-CHP systems employed for residential users, thanks to the optimized operation strategy and fine-tuned coupling of their components.

In this paper, two residential users provided the basis to analyze different arrangements of the grid and the consequent optimized operation strategy of the PMs. Four energy system configurations were evaluated and discussed: (1) reference scenario, (2) independent energy systems, (3) shared thermal and electrical energy storage and (4) shared storages and prime mover. In the "reference scenario," a domestic AB was used for meeting thermal energy demand, while the national electrical grid (EG) supplied electrical energy. In the "independent energy systems" configuration, each of the two residential users was equipped with its own independent energy system, which was composed of a PM, a TES, an EES and an AB. Both residential users were connected with the national electrical grid and were also connected with each other by means of a local DHG. In the configuration named "shared TES and EES," each user could exploit its own PM, AB and the connection to the EG. This means that one TES and one EES were shared between the two users. Finally, the "shared TES, EES and $\mathrm{PM}^{\prime \prime}$ configuration considered shared TES and EES, but the demand of both users was met by means of only one shared PM. 
The simulation model optimizes the operation strategy of the PMs in order to minimize the primary energy required to meet both the thermal and electrical energy demands. The energy demands are derived from published data and reproduce a winter day of a typical residential user.

The paper is organized as follows. Section 2 presents and discusses the modeling approach and the optimization strategy. Section 3 presents the case study and the system configurations. Section 4 reports the results in terms of primary energy consumption, PM working hours and thermal and electrical energy share. Section 4 also includes a feasibility analysis and a discussion about their mutual interaction and consequent effect on PM operation strategy. Finally, conclusions and guidelines are drawn.

\section{Methodology}

The energy system configurations evaluated in this paper account for three main components, namely PM, TES and EES. ABs and EG are also available by providing a backup system aimed at energy fulfillment. Both the PM and the backup systems meet electrical and thermal energy demands; in addition, in case of need, thermal energy can also be supplied by a DHG.

In this paper, the most suitable strategy to switch on/off the ABs or the PM (either alternatively or simultaneously) was identified by means of the optimization algorithm discussed in Section 2.3, to minimize primary energy consumption.

\subsection{Energy System Modeling}

As shown in Equation (1), the state of charge (SOC) of a TES at time point $(t+1)$ depends on the $S O C$ at the previous time point, i.e., $t$, and the thermal power $P_{\text {TES }}$ entering or leaving the TES. In addition, a thermal leakage rate, defined as in [37], is included to account for thermal leakages.

$$
S O C_{\mathrm{TES}}^{t+1}=\left(1-\epsilon_{\mathrm{th}}\right) \cdot\left(\operatorname{SOC}_{\mathrm{TES}}^{t}-P_{\mathrm{TES}} \cdot \Delta t\right)
$$

The thermal power $P_{\text {TES }}$ is calculated by means of Equation (2):

$$
P_{\text {TES }}=\sum_{\mathrm{i}=1}^{n_{\text {user }}}\left(P_{\text {th }, \text { user }, \mathrm{i}}-u_{\mathrm{i}} \cdot P_{\text {th }, \text { max }, \mathrm{i}}-P_{\text {th }, \mathrm{AB}, \mathrm{i}} \pm P_{\text {th }, \mathrm{DHG}, \mathrm{i}}\right)
$$

where $P_{\mathrm{TES}}$, i.e., the thermal power that enters or leaves the TES, depends on the thermal demand of the user $\left(P_{\text {th,user, } i}\right)$, the thermal power provided by the PM $\left(P_{\text {th,max }, \mathrm{i}}\right)$, the ABs $\left(P_{\mathrm{th}, \mathrm{AB}, \mathrm{i}}\right)$ and the DHG $\left(P_{\mathrm{th}, \mathrm{DHG}, \mathrm{i}}\right)$, which can be either entering or leaving. It is worth noting that $P_{\mathrm{th}, \mathrm{DHG}, \mathrm{i}}$ is null in the reference scenario, since the DHG is not included.

The SOC of each EES is estimated using Equation (3) by neglecting electrical energy leakages:

$$
S O C_{\mathrm{EES}}^{t+1}=\left(S O C_{\mathrm{EES}}^{t}-P_{\mathrm{EES}} \cdot \Delta t\right)
$$

The electric power entering or leaving the EES $\left(P_{\mathrm{EES}}\right)$ is calculated by means of Equation (4), which accounts for inverter efficiency $\left(\eta_{\text {inv }}\right)$ and EES charging efficiency $\left(\eta_{\mathrm{ch}}\right)$.

$$
P_{\mathrm{EES}}=\left\{\begin{array}{c}
\eta_{\text {inv }} \cdot\left(\sum_{\mathrm{i}=1}^{n_{\text {user }}} P_{\mathrm{el}, \mathrm{user}, \mathrm{i}}-u_{\mathrm{i}} \cdot P_{\mathrm{el}, \mathrm{max}, \mathrm{i}}-P_{\mathrm{el}, \mathrm{EG}, \mathrm{i}}^{+}\right) \text {if } \sum_{\mathrm{i}=1}^{n_{\text {user }}} P_{\mathrm{el}, \mathrm{user}, \mathrm{i}}-u_{\mathrm{i}} \cdot P_{\mathrm{el}, \mathrm{max}, \mathrm{i}}-P_{\mathrm{el}, \mathrm{EG}, \mathrm{i}}^{+}>0 \\
\eta_{\mathrm{inv}} \eta_{\mathrm{ch}} \cdot\left(\sum_{\mathrm{i}=1}^{n_{\text {user }}} P_{\mathrm{el}, \mathrm{user}, \mathrm{i}}-u_{\mathrm{i}} \cdot P_{\mathrm{el}, \mathrm{max}, \mathrm{i}}-P_{\mathrm{el}, \mathrm{EG}, \mathrm{i}}^{+}\right) \text {if } \sum_{\mathrm{i}=1}^{n_{\text {user }}} P_{\mathrm{el}, \mathrm{user}, \mathrm{i}}-u_{\mathrm{i}} \cdot P_{\mathrm{el}, \mathrm{max}, \mathrm{i}}-P_{\mathrm{el}, \mathrm{EG}, \mathrm{i}}^{+} \leq 0
\end{array}\right.
$$

If the two conditions reported in Equation (5a) are satisfied,

$$
\left\{\begin{array}{c}
S O C_{\mathrm{EES}}=S O C_{\mathrm{EES}, \max } \\
\sum_{\mathrm{i}=1}^{n_{\text {user }}} P_{\mathrm{el}, \mathrm{user}, \mathrm{i}}-u_{\mathrm{i}} \cdot P_{\mathrm{el}, \text { max }, \mathrm{i}}-P_{\mathrm{el}, \mathrm{EG}, \mathrm{i}}^{+}<0
\end{array}\right.
$$


then the excess of electrical energy produced by the PM is sent to the EG, as given in Equation (5b), by assuming that any excess of energy can be accepted by the national EG. It is worth noting that this assumption is justified by the fact that most EU countries favor the electricity generated by means of CHP units and priority dispatching.

$$
E_{\mathrm{el}, \mathrm{EG}}^{-}=\left(u \cdot P_{\mathrm{el}, \max }-P_{\mathrm{el}, \mathrm{user}}\right) \cdot \Delta t
$$

\subsection{Objective Function}

Primary energy consumption $E_{\mathrm{p}}$, defined in Equation (6), accounts for the primary energy required by all the available PMs, ABs and EG to meet both thermal and electrical energy demand.

$$
E_{\mathrm{p}}=\left(\sum_{\mathrm{i}=1}^{n_{\mathrm{PM}}} \frac{u_{\mathrm{i}} \cdot P_{\mathrm{el}, \mathrm{max}, \mathrm{i}}}{\eta_{\mathrm{PM}, \mathrm{i}}\left(u_{\mathrm{i}}\right)}+\frac{P_{\mathrm{th}, \mathrm{AB}, \mathrm{i}}}{\eta_{\mathrm{AB}, \mathrm{i}}}+\frac{P_{\mathrm{el}, \mathrm{EG}, \mathrm{i}}}{\eta_{\mathrm{EGm}} \cdot p}\right) \cdot \Delta t
$$

As can be seen in Equation (6), primary energy consumption depends on the electrical and thermal efficiency of the PMs, ABs and EG. More in detail, the electrical efficiency of each PM $\left(\eta_{\mathrm{PM}, \mathrm{i}}\right)$ depends on its load $u_{\mathrm{i}}$, which usually ranges from $0 \%$ to $100 \%$ (i.e., design point). The $\mathrm{AB}$ efficiency $\left(\eta_{\mathrm{AB}, \mathrm{i}}\right)$ is selected by considering a standard non-condensing unit (see Section 3).

The primary energy employed to produce electricity in the national electrical grid depends on its efficiency $\eta_{\mathrm{EGm}}$ (this is a mean value, depending on the considered country and generation technologies) and grid losses, by means of the parameter $p$ that also depends on the considered country.

\subsection{Optimization Algorithm}

As previously mentioned, this study makes use of DP [43], to identify the absolute minimum of a given objective function, as well as meeting user-defined constraints. A DP model, which is a sequential decision process, is characterized by states and decisions. The former, i.e., the "state," provides a picture of the situation at a given time point by allowing the evaluation of alternative courses of action. The latter, i.e., the "decision" also called "control variable", is an action that modifies the state, until a final state is achieved.

The alternating sequence of states and decisions constitutes the path through the state space. The DP algorithm requires a discrete and static time model of the systems. In fact, DP works backward; the algorithm starts from the final time point and goes back until the initial time point is reached.

Benefits of the DP algorithm were reported in several research papers, for example, [53]. With respect to other optimization strategies, DP is generally exploited thanks to (i) its efficiency, (ii) its independence from the linearity or nonlinearity of the problem and (iii) its capability to identify a solution that represents the global optimum.

The control variables and states considered in this paper are listed in Table 1. The control variables were four, i.e., one per each component. All the possible combinations of values of these control variables were analyzed across the selected time frame, to achieve the minimization of the objective function (in this paper, overall primary energy consumption). Instead, the two states were the SOCs of the TES and the EES. It is worth noting that an increase of the number of states makes the computational time increase exponentially and thus modeling efforts are usually made to reduce its number.

Table 1. Control variables and states.

\begin{tabular}{ccc}
\hline Energy System Component & Variable & $\begin{array}{c}\text { DP (Dynamic Programming) } \\
\text { Component }\end{array}$ \\
\hline PM (prime mover) & $u$ & Control variable \\
AB (auxiliary boiler) & $P_{\text {th, } \mathrm{AB}}$ & Control variable \\
DHG (district heating grid) & $P_{\text {th, } \mathrm{DHG}}$ & Control variable \\
EG (electrical grid) & $P_{\mathrm{el}, \mathrm{EG}}$ & Control variable \\
\hline TES (thermal energy storage) & $S_{\mathrm{SOC}} \mathrm{TES}$ & State \\
EES (electrical energy storage) & $S_{\mathrm{EES}}$ & State \\
\hline
\end{tabular}


All the analyses carried out in this paper were performed in the Matlab ${ }^{\circledR}$ environment. In particular, the DP algorithm was implemented based on the routine developed by [54] and available at [55].

\section{Case Study}

\subsection{Energy System Configuration}

The case study considered two residential users. Four configurations, i.e., (1) reference scenario, (2) independent energy systems, (3) shared TES and EES and (4) shared TES, EES and PM, were analyzed. Thus, with respect to Cattozzo et al. [52], the "independent energy systems" scenario was also investigated in this paper.

"Reference scenario". In the "reference scenario", sketched in Figure 1, thermal energy demand was met by an $\mathrm{AB}$ (one for each user), while electrical energy demand was supplied by the EG.

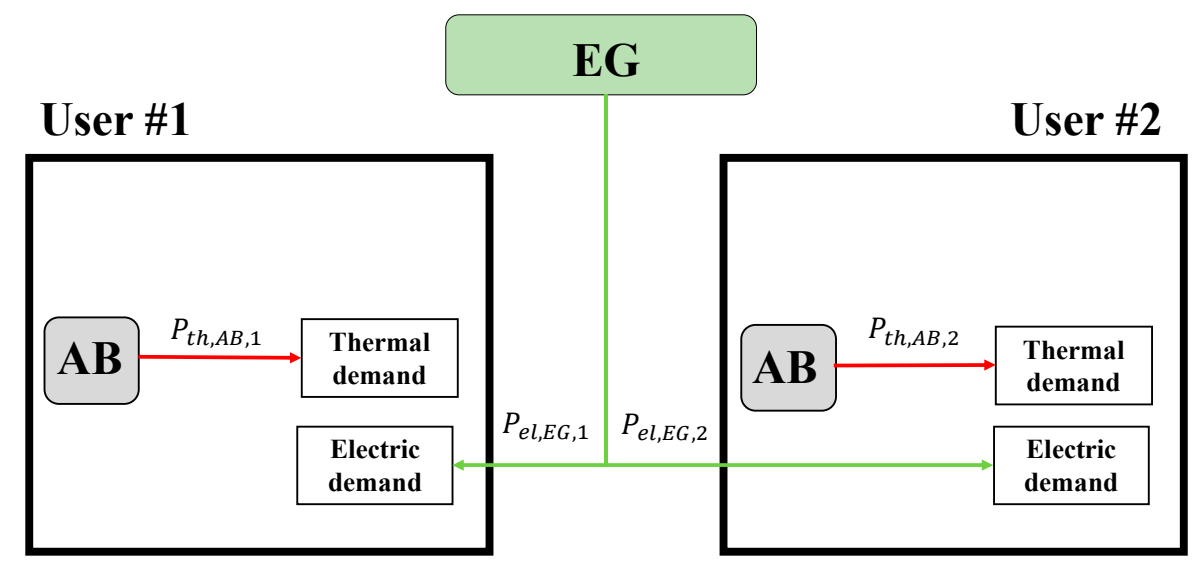

Figure 1. Reference scenario.

"Independent energy systems". Figure 2 shows the "independent energy systems" configuration, in which each of the two residential users was equipped with its own independent energy system. Each energy system was composed of a PM, a TES, an EES and an AB. Both residential users were connected with the national EG and were also connected with each other by means of a local DHG.

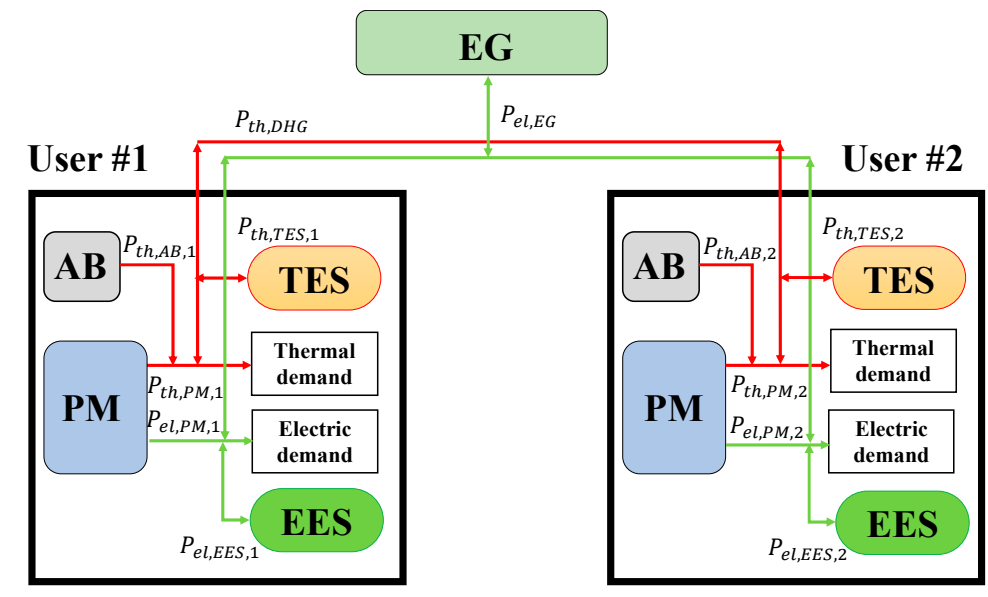

Figure 2. CHP scenario with independent energy systems.

"Shared TES and EES". The "shared TES and EES" configuration accounts for one AB and one PM for each user (see Figure 3). In addition, each user was connected to the national EG. Thus, in this case, the storages were shared by the users. 


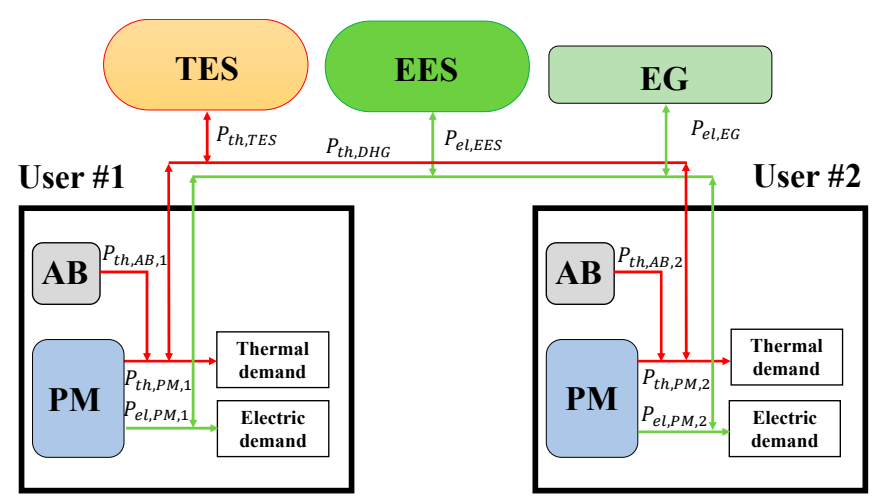

Figure 3. CHP scenario with shared TES and EES.

"Shared TES, EES and PM". This configuration, namely "shared TES, EES and PM", aimed at peak shaving between the users and was consequently expected to increase the number of PM working hours. In fact, in this configuration (see Figure 4), one PM was shared by the two users to meet their energy demand.

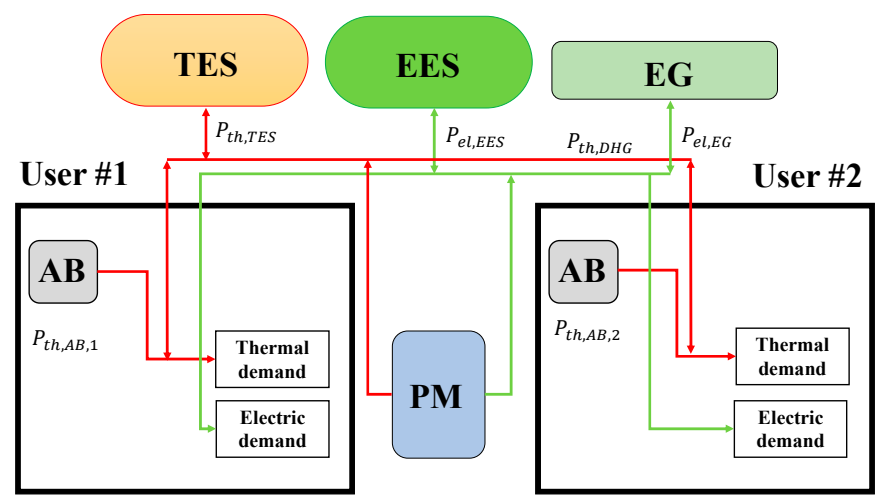

Figure 4. CHP scenario with shared TES, EES and PM.

\subsection{User Energy Demand}

The thermal and electrical energy demands required by both residential users, i.e., user 1 and user 2, are sketched in Figure 5a,b. These trends, which were also used in [52], refer to a typical winter day. In particular, the energy demand required by user 1 was derived by [56], while the energy demand of user 2 was obtained by imposing small random variations on the demand of the user 1 . In this manner, the two energy demands were slightly different, but comparable. The same trend of the user 1 was also used in [14] for evaluating the capability of micro-CHP systems to meet the household energy demands of single-family users and in [57] for analyzing the transient behavior of micro-CHP systems.

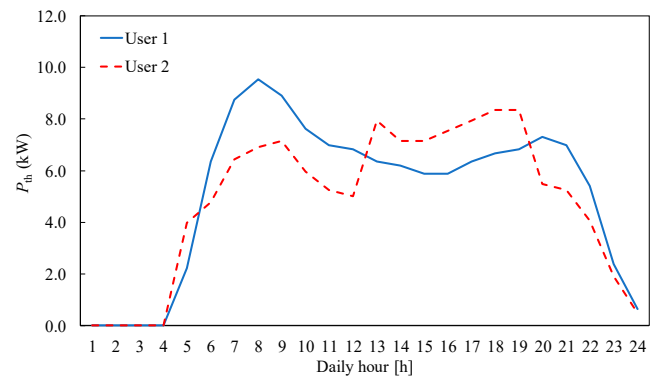

(a)

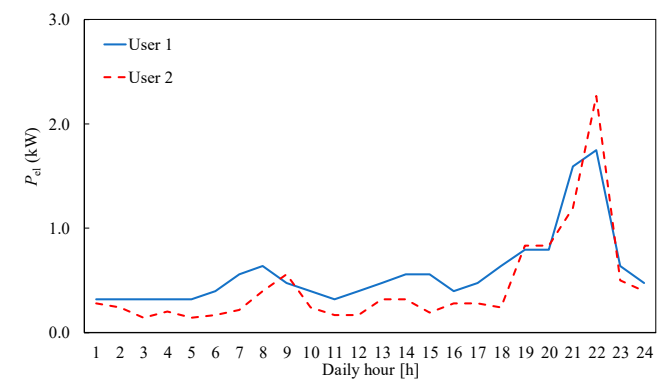

(b)

Figure 5. Daily power demand of two users: (a) thermal power, (b) electric power. 
In any case, it must be highlighted that the overall results presented in Section 4 do not depend on the number of considered users, since they just scale if more users are modeled.

\subsection{Prime Mover}

Because of their current market availability [57-60], even for low electric power outputs (as low as $1 \mathrm{~kW}$ [14]), the PM was an internal combustion engine, named Honda Ecowill. The nominal values of electric and thermal power outputs and efficiencies are reported in Table 2 for the considered engine. The electric power output is equal to $1 \mathrm{~kW}$. In this paper, PM load modulation was not allowed, i.e., only two operation modes were possible for the PM, i.e., no load or full load.

Table 2. Prime mover nominal performance.

\begin{tabular}{cccccc}
\hline $\mathbf{P M}$ & $\boldsymbol{P}_{\text {el }}(\mathbf{k W})$ & $\boldsymbol{P}_{\text {th }}(\mathbf{k W})$ & $\eta_{\text {el }}$ & $\eta_{\text {th }}$ & Ref. \\
\hline Honda Ecowill & 1.00 & 3.25 & 0.200 & 0.630 & {$[14]$} \\
\hline
\end{tabular}

It must be also highlighted that, when multiple PMs were considered for meeting a given demand (scenarios "Independent energy systems" and "Shared TES and EES"), the PMs were of the same type.

\subsection{Electrical and Thermal Energy Storage}

The capacity of the TES and EES is a key factor to optimize CHP system operation and meet a given energy demand in an effective way, as well as the proper sizing and scheduling of storage systems heavily affect their application [61]. For this reason, a sensitivity analysis was performed on both the TES and EES capacities for the "independent energy systems" configuration, in order to evaluate the respective optimal size. The TES sizes (10 and $15 \mathrm{kWh})$ and EES sizes ( 2.5 and $5.0 \mathrm{kWh})$ were selected in agreement with the users' energy demand and by evaluating similar applications reported in [62].

Instead, in the "shared TES and EES" and "shared TES, EES and PM" configurations the sensitivity analysis was not carried out and the sizes were assumed equal to twice the optimal TES and EES sizes identified for the "independent energy systems" configuration.

\subsection{System Parameters}

The system parameters reported in Table 3 are assumed constant. In fact, in practice, they cannot be optimized by the user, but are driven by standards (e.g., $\eta_{\mathrm{AB}}$ and $p$ ) or depend on the national grid (i.e., $\left.\eta_{\mathrm{EGm}}\right)$. Finally, the two efficiencies $\eta_{\text {inv }}$ and $\eta_{\mathrm{ch}}$ are usually very high and thus their variation negligibly influence the results.

Table 3. Constant model parameters.

\begin{tabular}{ccc}
\hline Efficiency & Value & Reference \\
\hline$\eta_{\mathrm{AB}}$ & 0.900 & {$[63]$} \\
$\eta_{\mathrm{EG}}$ & 0.460 & {$[64]$} \\
$p$ & 0.851 & {$[63]$} \\
$\eta_{\text {inv }}$ & 0.94 & {$[65]$} \\
$\eta_{\mathrm{ch}}$ & 0.98 & Assumption \\
\hline
\end{tabular}

\subsection{Control Variables and States}

The range of discretization and variation of the control variables and states are reported in Table 4 . The assumptions made are discussed as follows. 
Table 4. Control variables and states.

\begin{tabular}{ccccc}
\hline Energy System Component & Variable & Minimum Value & Maximum Value & Discretization \\
\hline PM & $u$ & 0 & 1 & Binary value \\
AB & $P_{\text {th, } \mathrm{AB}}$ & $0 \mathrm{~kW}$ & $24 \mathrm{~kW}$ & 5 steps \\
DHG & $P_{\text {th, } \mathrm{HHG}}$ & $-P_{\text {th,user,max }}$ & $+P_{\text {th,user,max }}$ & 5 steps \\
EG & $P_{\mathrm{el}, \mathrm{EG}}$ & 0 & $+P_{\mathrm{el}, \mathrm{user} \text {,max }}$ & 5 steps \\
\hline TES & $S O C_{\mathrm{TES}}$ & $5 \% S O C_{\mathrm{TES}, \max }$ & $95 \% S O C_{\mathrm{TES}, \max }$ & Continuous \\
EES & $S O C_{\mathrm{EES}}$ & $5 \% S O C_{\mathrm{EES}, \max }$ & $95 \% S O C_{\mathrm{EES}, \max }$ & Continuous \\
\hline
\end{tabular}

The load $u$ can only be 0 , i.e., the PM is not working, or 1, i.e., the PM works at nominal load. The nominal thermal power of the $A B$ is $24 \mathrm{~kW}$, which is a typical value for household applications $[14,18,29]$. The maximum thermal power exchanged through the DHG does not exceed the PM nominal power output. Finally, the electrical energy supplied by the national grid is equal to the maximum electrical energy demand of the user, at maximum.

It is clear that an infinitely fine discretization of the control variables can lead to the most optimized result. However, this also makes the computational cost increase dramatically, since DP solver is particularly time consuming. Therefore, as a trade-off between accuracy and computational time, five discrete values are considered for the $\mathrm{AB}, \mathrm{DHG}$ and $\mathrm{EG}$ control variables.

The two states $S O C_{\mathrm{TES}}$ and $S O C_{\mathrm{EES}}$, which are the output of the DP algorithm, are identified by means of a continuous function that ranges from 5\% to 95\% of the TES and EES nominal capacity. In such a manner, the TES and EES cannot be completely charged and discharged taking into accounted their actual technical limits.

Finally, by considering real-world operation of internal combustion reciprocating engines, the minimum switch-on time frame of the PM was assumed equal to 30 minutes.

\section{Results}

The simulated period was selected to be a working week composed of six identical winter days, of which the energy demand is shown in Figure 5. Another reason for selecting such a timeframe is that $S O C$ relative variation across the considered time frame is lower than $1.5 \%$ for all the analyzed configuration and component sizes.

The analyses carried out in this paper were aimed at evaluating (i) primary energy consumption, (ii) PM working hours, (iii) thermal and electrical energy share and (iv) optimal operation strategy identified by the DP algorithm, which allows the minimization of the primary energy consumption.

Finally, it must be considered that in the three scenarios that consider the presence of at least one PM (i.e., all the scenarios with the exception of the reference scenarios), electrical energy could be delivered to the EG (see Equation (5b)). For this reason, the primary energy used to produce such electricity was added to the electrical energy produced in the corresponding reference scenario. Thus, the production of useful energy (electrical and thermal) was exactly the same and primary energy consumption values could be coherently compared.

\subsection{Primary Energy Consumption and PM Working Hours}

"Independent energy systems". As outlined in Figure 6, the primary energy consumption related to the CHP scenario was slightly dependent on TES and EES sizes. Compared to the "reference scenario", the primary energy consumption saved by means of the independent energy system configuration ranged from $3.9 \%$ (with the highest TES and EES capacity values) to $4.6 \%$ (with the lowest TES and EES capacity values).

Figure 7 shows the rate of PM working hours (defined as the ratio of the number of working hours and the maximum number of working hours during six days) corresponding to the primary energy consumption values reported in Figure 6. The rate of PM working hours confirms to be quite unaffected by TES and EES sizes. Therefore, the TES and EES of minimum capacities (10 and $2.5 \mathrm{kWh}$, respectively) 
proved to be the optimal solution both in terms of primary energy consumption (1.89 MWh) and PM working hours (58\% for PM 1 and 47\% for PM 2, see Table 5).

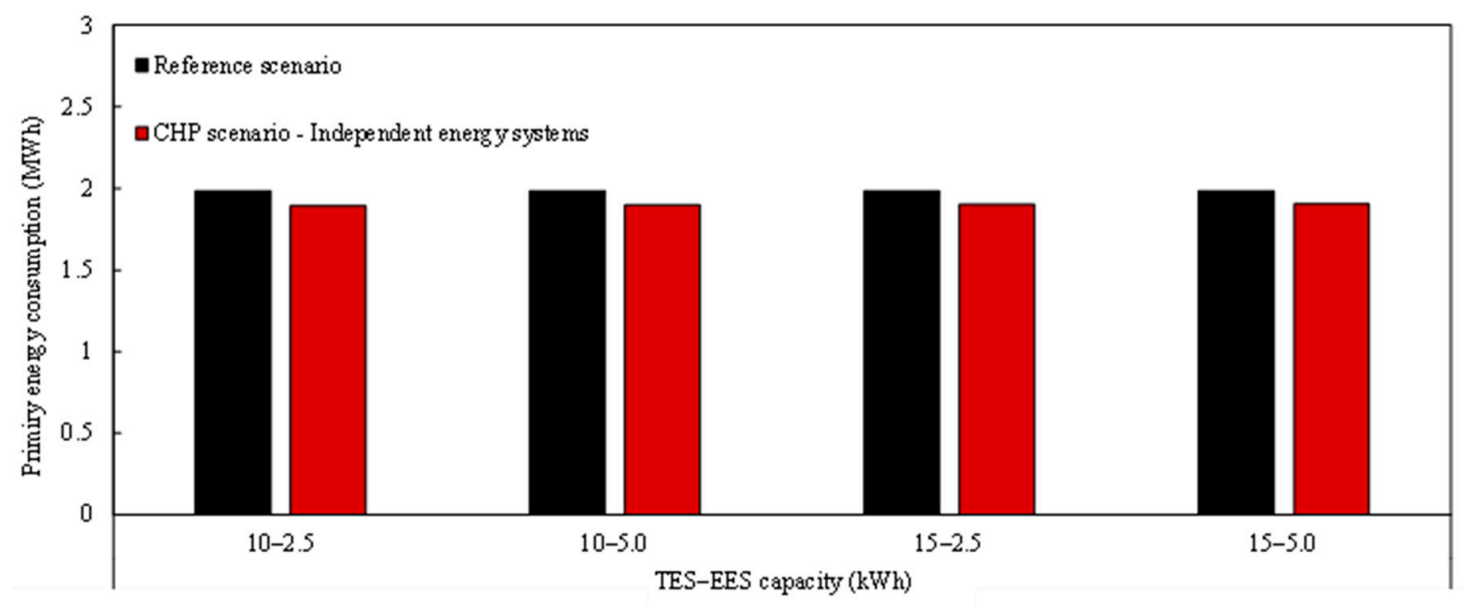

Figure 6. Primary energy consumption with independent energy systems.

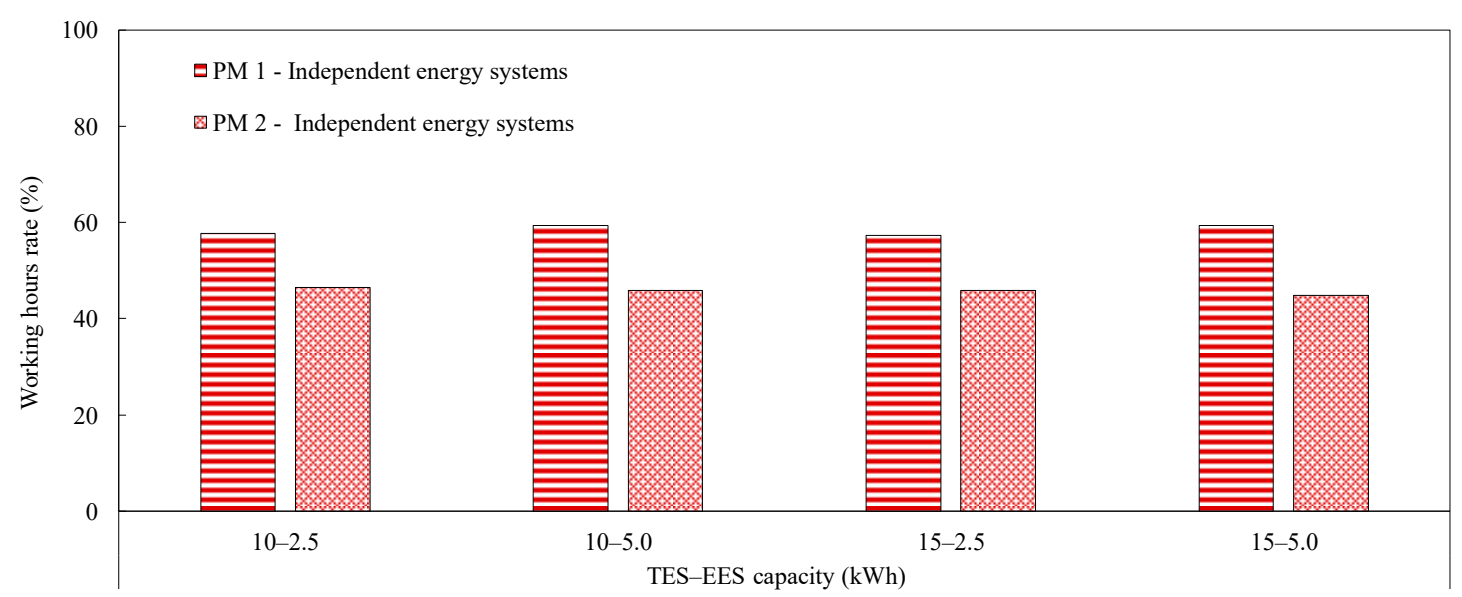

Figure 7. Rate of PM working hours with independent energy systems.

Table 5. Primary energy consumption and rate of PM working hours.

\begin{tabular}{|c|c|c|c|c|}
\hline & \multirow{2}{*}{$\begin{array}{l}\text { Reference } \\
\text { Scenario }\end{array}$} & \multicolumn{3}{|c|}{ CHP Scenario } \\
\hline & & $\begin{array}{l}\text { “Independent } \\
\text { energy systems" } \\
\text { (TES: } 10 \mathrm{kWh} \\
\text { EES: } 2.5 \mathrm{kWh} \text { ) }\end{array}$ & $\begin{array}{l}\text { "Shared } \\
\text { TES and EES" } \\
\text { (TES: } 20 \mathrm{kWh} \text {; } \\
\text { EES: } 5 \mathrm{kWh} \text { ) }\end{array}$ & $\begin{array}{l}\text { "Shared } \\
\text { TES, EES and PM" } \\
\text { (TES: } 20 \mathrm{kWh} \text {; } \\
\text { EES: } 5 \mathrm{kWh} \text { ) }\end{array}$ \\
\hline $\begin{array}{l}\text { Primary energy } \\
\text { consumption }\end{array}$ & $1.98 \mathrm{MWh}$ & $1.89 \mathrm{MWh}$ & $1.88 \mathrm{MWh}$ & $1.91 \mathrm{MWh}$ \\
\hline $\begin{array}{c}\text { Rate of } \\
\text { PM working hours }\end{array}$ & N/A & $\begin{array}{l}58 \% \text { (PM 1) } \\
47 \% \text { (PM 2) }\end{array}$ & $\begin{array}{l}\text { 64\% (PM 1) } \\
26 \% \text { (PM 2) }\end{array}$ & 81\% (shared PM) \\
\hline
\end{tabular}

"Shared TES, EES and PM". Table 5 reports both the primary energy consumption and rate of PM working hours associated with the "shared TES and EES" and "shared TES, EES and PM" configurations with only one TES and EES size (20 and $5 \mathrm{kWh}$, respectively) assumed to be twice the optimal capacities identified in the "independent energy systems" configuration. The primary energy saving compared to the "reference scenario" was equal to $5.1 \%$ if each user was equipped 
with one PM ("shared TES and EES configuration"). In this configuration, the rate of working hours was equal to $64 \%$ for PM 1, whereas it was equal to $26 \%$ for PM 2 . Instead, in the "shared TES, EES and PM configuration," the energy saving was equal to $3.7 \%$ and the shared PM ran for $81 \%$ of the considered timeframe.

\subsection{Energy Share}

The values of thermal and electrical energy share are reported in Figures 8 and 9, respectively. These figures also highlight the influence of the energy system configuration and storage sizing.

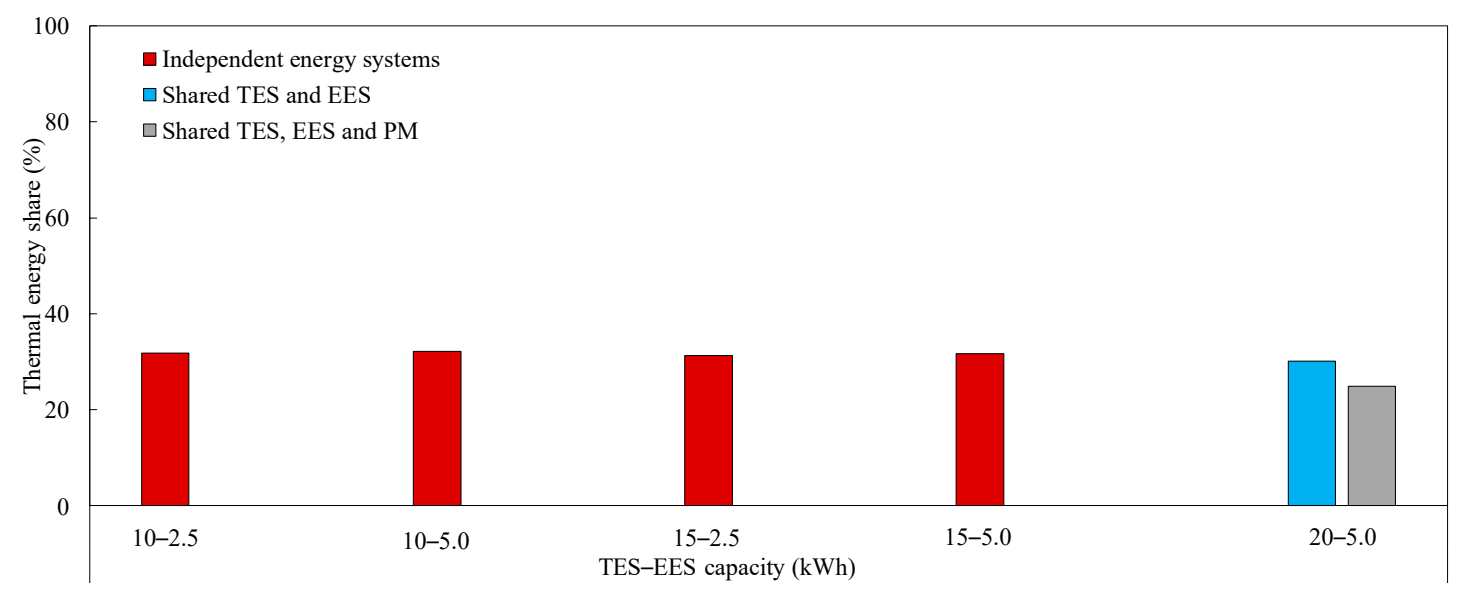

Figure 8. Thermal energy share.

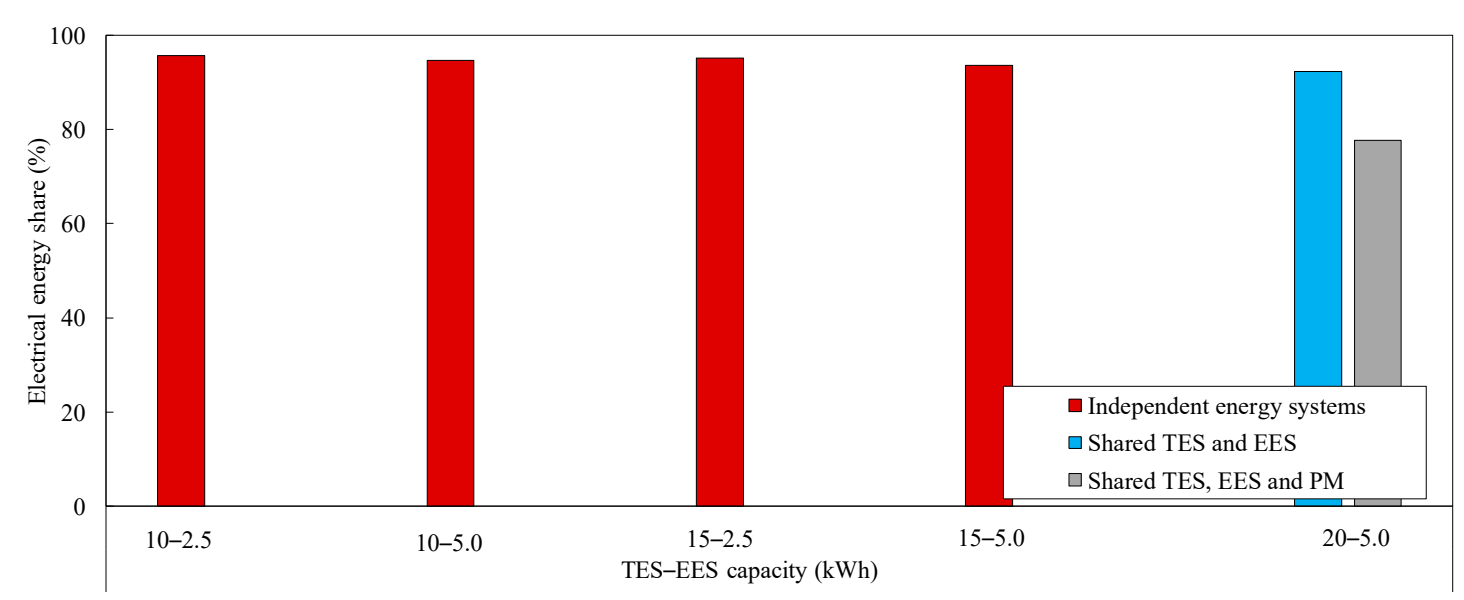

Figure 9. Electrical energy share.

Regardless of system configuration, the thermal energy share covered by the PMs was generally in the range $25-32 \%$ (see Figure 8 ). Thus, the remaining thermal energy demand had to be provided by the ABs.

Instead, as shown in Figure 9, the PMs met most of the electrical energy demand. Thus, the energy systems were generally self-sufficient, i.e., independent of the EG.

The analysis of the results reported in Figure 6 through Figure 9 and in Table 5 highlights that two energy system configurations were generally preferable: (i) "shared TES and EES," equipped with two Ecowill PMs and (ii) "shared TES, EES and PM," equipped with one Ecowill PM. These solutions represent the best configurations since they allowed almost the same primary energy consumption, but the PM ran longer than in the case of the "independent energy system" configuration and, in addition, the PM met most of the electrical energy demand. Moreover, it must be noted that primary 
energy consumption and working hours were slightly affected by TES and EES capacities, regardless of the considered energy system configuration.

\subsection{Optimized Strategy}

This paragraph reports an insight about the optimized strategies of the most suitable energy system configurations, i.e., (i) "shared TES and EES" and (ii) "shared TES, EES and PM". In both cases, the TES and EES capacities were the same, i.e., 20 and $5 \mathrm{kWh}$, respectively. More in detail, the PM and $\mathrm{AB}$ working conditions, the TES and EES state of charge and the power energy taken from and delivered to the national electrical grid are discussed. Figures 10 and 11 show the optimized strategies across six days for comparison purposes.
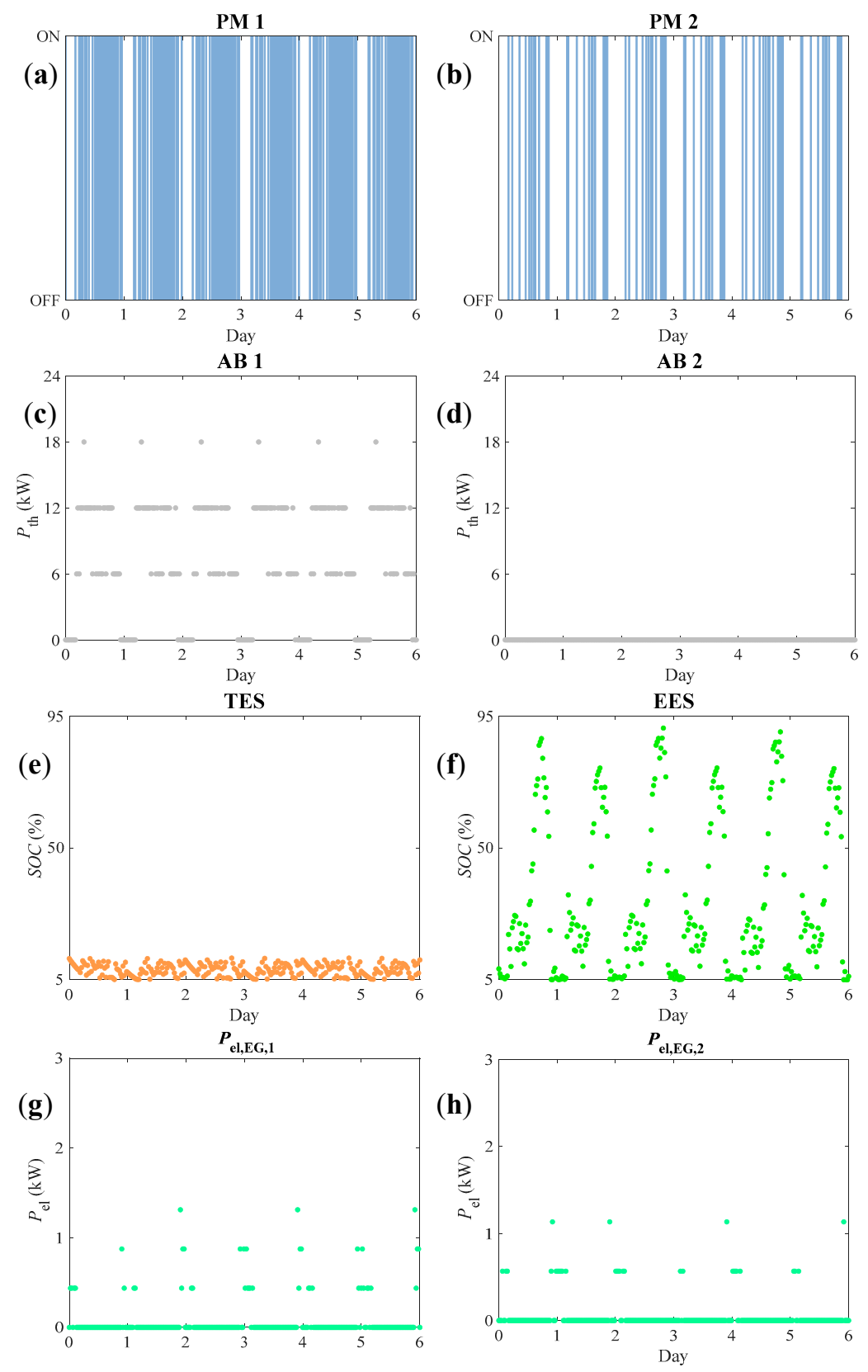

Figure 10. Best optimized strategy with "shared TES and EES": (a) PM 1 switch-on time; (b) PM 2 switch-on time; (c) thermal power supplied by AB 1; (d) thermal power supplied by AB 2; (e) state of charge of the TES; (f) state of charge of the EES; (g) electric power taken from the electrical grid by user 1 ; (h) electric power taken from the electrical grid by user 2. 

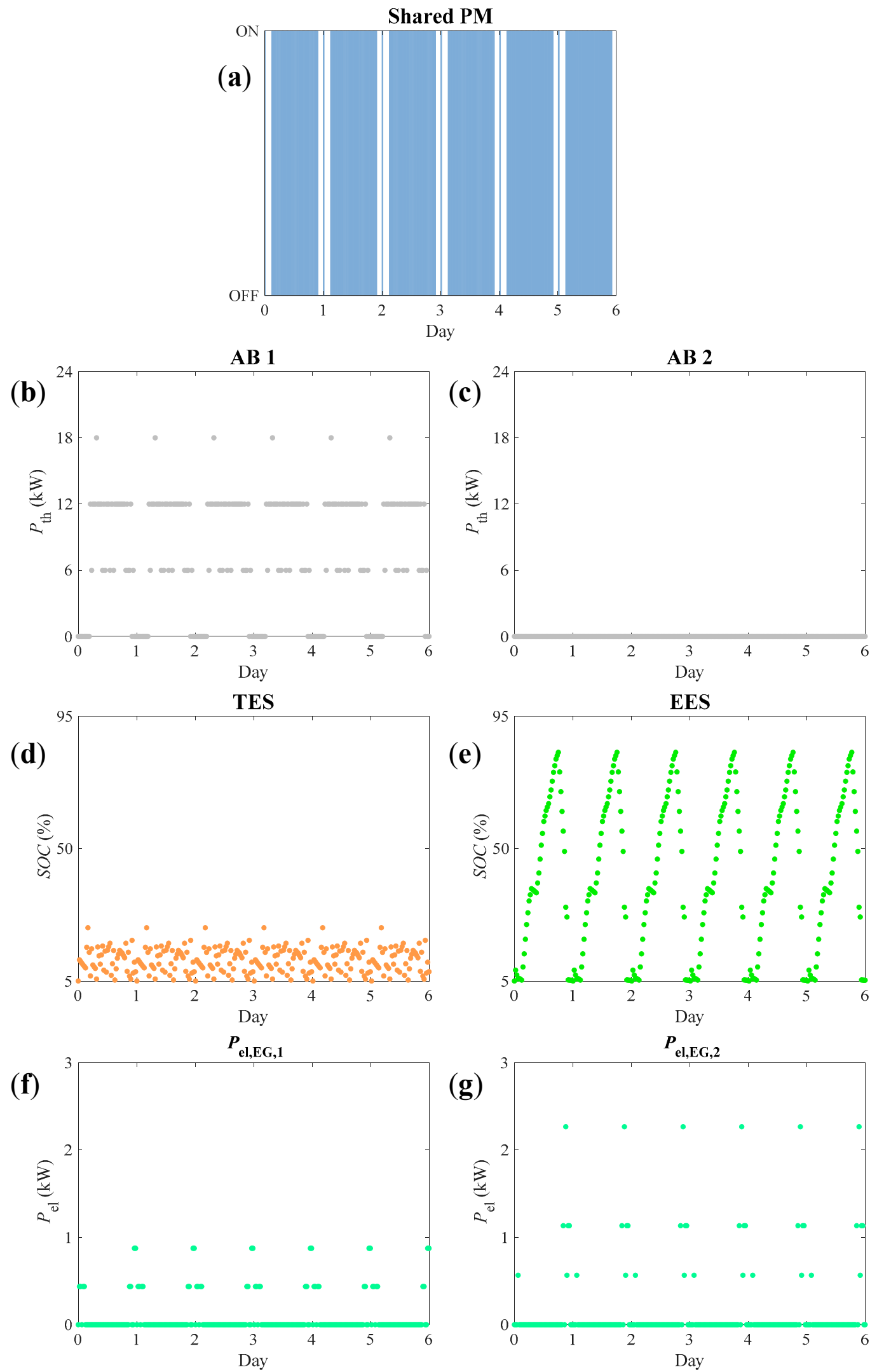

Figure 11. Best optimized strategy with "shared TES, EES and PM": (a) shared PM switch-on time; (b) thermal power supplied by AB 1; (c) thermal power supplied by AB 2; (d) state of charge of the TES; (e) state of charge of the EES; (f) electric power taken from the electrical grid by user 1; (g) electric power taken from the electrical grid by user 2. 


\subsubsection{Optimized Strategy with Shared TES and EES}

The "shared TES and EES" configuration which required the lowest primary energy consumption involved the following parameters:

- 2 Ecowill PMs;

- TES capacity, $20 \mathrm{kWh}$;

- $\quad$ EES capacity, $5.0 \mathrm{kWh}$.

In Figure 10a,b, the bar plots titled "PM 1" and "PM 2" show the switch-on time of the two PMs. It is worth noting that both PMs worked for a significant amount of hours, even if, as highlighted in Table 5, PM 1 covered most of the energy demand, while PM 2 generally worked for peak-shaving purposes. The two figures labeled "AB 1" and "AB 2" (Figure 10c,d) show the thermal power supplied by the ABs. As can be seen, the maximum thermal power $(24 \mathrm{~kW})$ was never supplied. In fact, $A B 1$ supplied at maximum $18 \mathrm{~kW}$ in correspondence of the maximum thermal power demand, while $A B 2$ was always switched off. As a result, the TES (Figure 10e) seems to be oversized since its SOC was always lower than $15 \%$. Instead, the SOC of EES (Figure 10f) reached the maximum value of $91 \%$.

By comparing the SOC of the EES and the electric power taken from the national electrical grid (see Figure 10g,h), it is evident that both users usually needed electric power from the national electrical grid at the same time points, i.e., when the SOC of the EES was at a minimum. In fact, electrical energy was taken from the grid, but it was never delivered to the grid.

\subsubsection{Optimized Strategy with Shared TES, EES and PM}

The details of the operation of the best optimized strategy with "shared TES, EES and PM" are reported in Figure 11. The CHP configuration included:

- 1 Ecowill PM;

- TES capacity, $20 \mathrm{kWh}$;

- EES capacity, $5.0 \mathrm{kWh}$.

In agreement with the results shown in Table 5, Figure 11a confirms that the shared PM worked almost all the day, with the exception of the beginning of the day (when only electric power was required) and the end of the day (when thermal and electrical energy was very low).

The daily thermal energy profile which was supplied by $A B 1$ was coherent with the thermal energy demand of the users; in fact, as sketched in Figure 11b, AB 1 started working as soon as the thermal energy was required and the maximum thermal power, i.e., $18 \mathrm{~kW}$, was supplied when the thermal peak demand occurred. On the contrary, AB 2 never worked (Figure 11c). Thus, since the AB nominal power (i.e., $24 \mathrm{~kW}$ ) was never supplied, $A B 1$ was oversized and $A B 2$ was redundant. As noted for the previous configuration, the TES capacity was significantly oversized; in fact, its maximum SOC was always lower than $25 \%$ (see Figure 11d). Instead, the SOC of the EES increased over time, with its maximum at roughly $80 \%$ (Figure 11e). Finally, both users had to take electrical energy from the national electrical grid (Figure 11f,g), both when the PM was switched off and at the end of the day. In fact, the PM and EES did not completely meet the power demand. As a result, the energy system never delivered electric power to the national electrical grid.

\subsection{Discussion}

The comprehensive analysis of Figures 6-11 and Table 5 allows the identification of the most suitable energy system configuration by integrating different pieces of information.

By comparing the two optimized strategies, it is clear that the thermal power supplied by AB 1 in both configurations was roughly the same. Moreover, in both cases AB 2 was redundant and TES and EES were always oversized since their maximum capacity was never exploited. As a result, the energy system configuration could be further simplified by sharing one $\mathrm{AB}$ and reducing the TES and EES 
sizes. Thus, the primary energy consumption would not vary, but the energy system installation costs can be reduced.

If both the TES and the EES were shared by the two residential users, the saving was increased to $5.1 \%$, while, if the PM was also shared, the saving with respect to the "reference scenario" dropped to $3.7 \%$, but the cost of one PM could be avoided. It should be noted that the saving of primary energy consumption was affected by the low size of the CHP system $(1 \mathrm{kWe})$ used, characterized by low electrical and thermal efficiency values ( $20 \%$ and $63 \%$, respectively). Moreover, it should also be noted that other studies document a comparable decrease of primary energy consumption $[48,52,66]$.

\subsection{Economic Feasibility}

This section evaluates the economic feasibility of the two most suitable energy system configurations ("shared TES and EES" and "shared TES, EES and PM") by considering the respective optimized strategy (see Section 4.3.), i.e., the one that allowed the lowest primary energy consumption. The economic feasibility of these two configurations is compared to that of the "reference scenario".

In the "reference scenario", the costs considered are the investment and maintenance cost of the $\mathrm{ABs}$, the purchase cost of natural gas used to feed the ABs and electricity purchase cost.

Instead, in the "shared TES and EES" and "shared TES, EES and PM" configurations, the following investment costs are attributed to system components:

- one or two PMs (two PMs in the "shared TES and EES" configuration, one PM in the "shared TES, EES and PM" configuration);

- one AB (in fact, as shown in Figures 10 and 11, one of the two ABs was always switched off);

- one TES;

- one EES.

For the investment costs, a straight-line amortization over 10 years is considered by assuming that amortization costs are charged only over the winter period (180 days), while the discount rate is assumed equal to $5 \%$.

Maintenance costs are accounted for in the following system components:

- one or two PMs (see the comment above),

- $\quad$ one $\mathrm{AB}$ (see the comment above),

- one TES.

Instead, the maintenance cost of the EES is neglected, according to [67].

Moreover, for the "shared TES and EES" and "shared TES, EES and PM" configurations, natural gas purchase cost and electricity purchase cost are also included as required in the "reference scenario," while it must be noted that electrical energy is not delivered to the national electrical grid and thus the possible corresponding revenue is null.

The purchase cost of electricity and natural gas assumed in this analysis refers to the Italian market in the first week of 2019 for households and varies on an hourly basis. In such a week, the hourly specific overall cost varied from 115.0 to $177.3 € / \mathrm{MWh}$, with an average value of $154.6 € / \mathrm{MWh}$. The cost of natural gas is assumed constant and equal to $0.23 € / \mathrm{Sm}^{3}$, in line with the Italian natural gas market.

Table 6 summarizes the assumptions made for carrying out the feasibility analysis. It should be noted that two different EES technologies [67], i.e., lead-acid battery $(171 € / \mathrm{kWh})$ or Li-ion battery $(844 € / \mathrm{kWh})$, are considered. Moreover, it must be highlighted that the investment cost of the PM is estimated as a trade-off value which renders the yearly cash flow of the two "shared TES and EES" and "shared TES, EES and PM" configurations equal to the yearly cash flow in the "reference scenario." Therefore, such a value represents the maximum allowable investment cost of the PM to make the two "shared TES and EES" and "shared TES, EES and PM" configurations economically equivalent with respect to the "reference scenario." Otherwise, incentives should be provided to make the PM investment cost affordable. 
Table 6. Assumptions for the feasibility analysis.

\begin{tabular}{|c|c|c|}
\hline Energy System Component & Investment Cost & Maintenance Cost \\
\hline PM & Estimated & $22.5 € /$ MWh [68] \\
\hline $\mathrm{AB}$ & $100 € / \mathrm{kW}$ & $2 \%$ of investment cost [69] \\
\hline TES & $10 € / \mathrm{kWh}[70]$ & $50 € /$ year [71] \\
\hline EES & $171 € / \mathrm{kWh}[67]$ or $844 € / \mathrm{kWh}[67]$ & $0[67]$ \\
\hline
\end{tabular}

Table 7 reports the trade-off value of the investment cost of the PM for the two considered configurations and two EES technologies.

Table 7. Trade-off value of the investment cost of the PM.

\begin{tabular}{ccc}
\hline System Configuration & Lead-Acid Battery (171 $\mathbf{\epsilon} / \mathbf{k W h})$ & Li-Ion Battery (844 $\mathbf{\epsilon} / \mathbf{k W h})$ \\
\hline Shared TES and EES & $2000 € / \mathrm{kW}$ & $300 € / \mathrm{kW}$ \\
\hline Shared TES, EES and PM & $4000 € / \mathrm{kW}$ & $450 € / \mathrm{kW}$ \\
\hline
\end{tabular}

If a lead-acid battery is employed, the PM investment cost should be lower than $2000 € / \mathrm{kW}$ for the "shared TES and EES" configuration, whereas it is doubled if the "shared TES, EES and PM" configuration is considered. Instead, if a Li-ion battery is considered, the PM investment cost should be lower than $450 € / \mathrm{kW}$.

However, as sketched in Figures 10 and 11 and discussed in Section 4.4, the shared TES is oversized. Thus, TES capacity may be even halved. However, such a solution does not significantly affect the results, since the maximum allowable investment cost of the PM would be increased by $100 € / \mathrm{kW}$ at maximum.

The economic viability of micro-CHP systems used in residential applications may be further improved by considering that several configurations investigated in this paper allow electrical energy to be delivered to the national electrical grid. Several recent studies investigated the potential synergy between micro-CHP systems and electric vehicle charging. The profitability of micro-CHP systems is thus expected to significantly improve, as demonstrated in [72,73], also thanks to optimized strategies and algorithms for smart charging control systems [74]. Moreover, incentives can be provided to make micro-CHP technologies more attractive.

\section{Conclusions}

This paper compared different configurations of micro-CHP systems and different sizing of both TES and EES, in order to minimize the primary energy consumption of two residential users.

One of the main outcomes of this paper is that primary energy consumption is slightly affected by the TES and EES size. This result, which differs from most studies reported in the literature, is obtained thanks to the operation strategy identified through a dynamic programming algorithm.

Another significant achievement is the quantification of the primary energy saving that can be achieved by exploiting micro-CHP technologies. The saving can be as high as $4.6 \%$ by considering the independent energy system configuration. If both the TES and the EES are shared among the two residential users, the saving is increased to 5.1\%; if the PM is also shared, then the saving with respect to the reference scenario drops to $3.7 \%$, but the cost of one PM can be avoided. Such a result was complemented with the analysis of the optimized operation strategy identified by the dynamic programming algorithm. In fact, one auxiliary boiler proved in practice useless and can be thus avoided, so that energy system installation costs are further reduced.

Finally, the economic feasibility was also evaluated with respect to the reference scenario by considering two EES technologies. Such analysis revealed that, in the most favorable case, PM investment cost can be as high as $4000 € / \mathrm{kW}$. 
Future work will investigate the capability of the optimized strategy by also incorporating renewable energy technologies.

Author Contributions: L.M., M.C., P.R.S., M.V. and H.B. conceived and designed the experiments; L.M., M.C., P.R.S., M.V. and H.B. performed the experiments; L.M., M.C., P.R.S., M.V. and H.B. analyzed the data; L.M., M.C., P.R.S., M.V. and H.B. wrote the paper. All authors have read and agreed to the published version of the manuscript.

Acknowledgments: This paper was carried out in the framework of the research program “ENERGYNIUS-ENERGY Networks Integration for Urban Systems (PG/2018/632084).”

Conflicts of Interest: The authors declare no conflict of interest.

\section{Nomenclature}

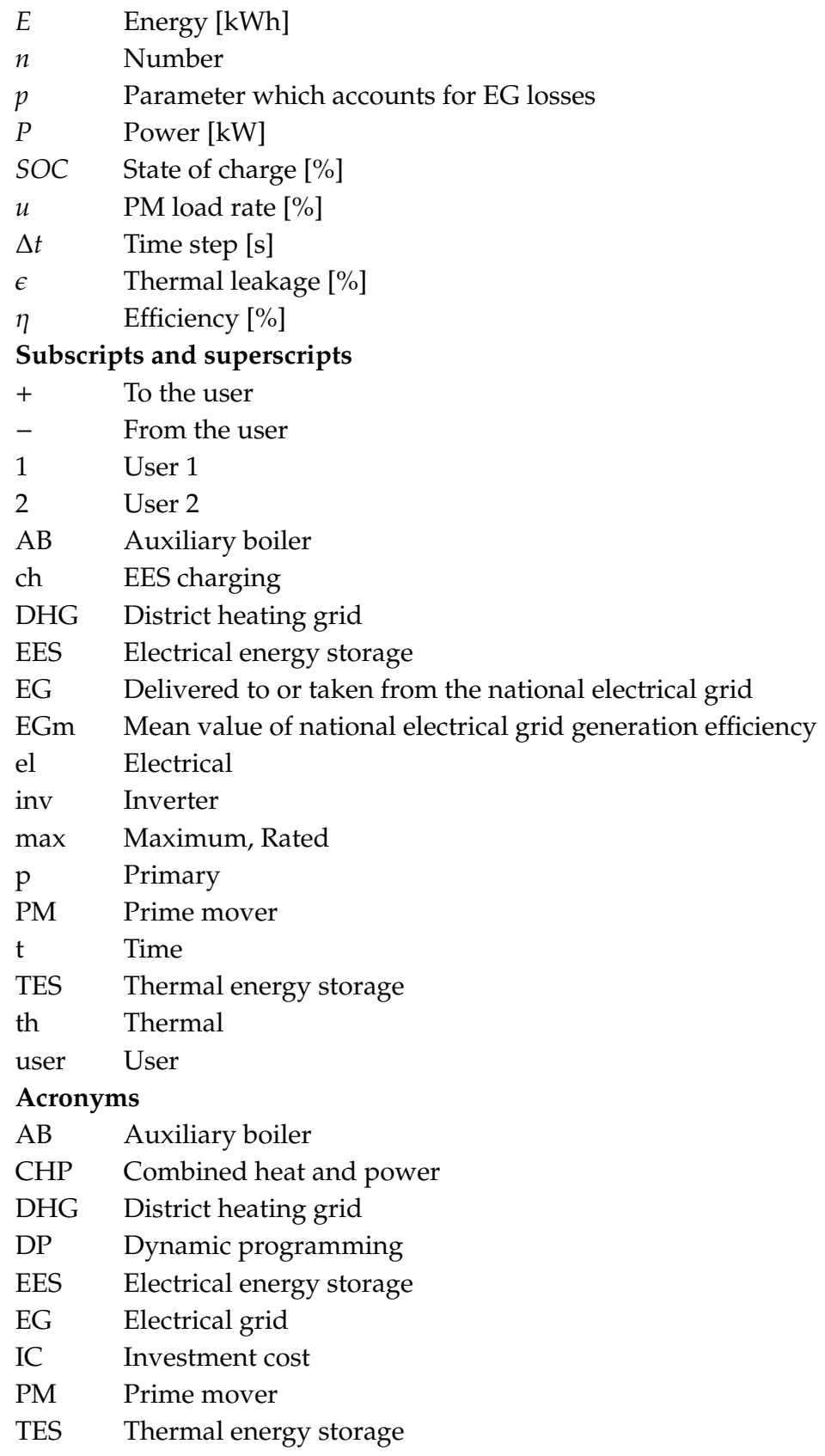

\section{References}

1. Barbieri, E.S.; Melino, F.; Morini, M. Influence of the thermal energy storage on the profitability of micro-CHP systems for residential building applications. Appl. Energy 2012, 97, 714-722. [CrossRef] 
2. Transforming Our World: The 2030 Agenda for Sustainable Development, A/RES/70/1. Available online: https://sustainabledevelopment.un.org (accessed on 3 February 2020).

3. Available online: https://ec.europa.eu/clima/policies/strategies/2030_en (accessed on 3 February 2020).

4. Caliano, M.; Bianco, N.; Graditi, G.; Mongibello, L. Economic optimization of a residential micro-CHP system considering different operation strategies. Appl. Therm. Eng. 2016, 101, 592-600. [CrossRef]

5. Andersen, A.N.; Østergaard, P.A. A method for assessing support schemes promoting flexibility at district energy plants. Appl. Energy 2018, 225, 448-459. [CrossRef]

6. De Pascali, P.; Bagaini, A. Energy transition and urban planning for local development. A critical review of the evaluation of integrated spatial and energy planning. Energies 2019, 12, 35. [CrossRef]

7. Cho, H.; Luck, R.; Eksioglu, S.; Chamra, L.M. Cost-optimized real-time operation of CHP systems. Energy Build. 2009, 41, 445-451. [CrossRef]

8. Sameti, M.; Haghighat, F. Optimization approaches in district heating and cooling thermal network. Energy Build. 2017, 140, 121-130. [CrossRef]

9. Yin, S.; Xia, J.; Jiang, Y. Characteristics Analysis of the Heat-to-Power Ratio from the Supply and Demand Sides of Cities in Northern China. Energies 2020, 13, 242. [CrossRef]

10. Soares, J.; Ghazvini, M.A.F.; Vale, Z.; Oliveira, P.M. A multi-objective model for the day-ahead energy resource scheduling of a smart grid with high penetration of sensitive loads. Appl. Energy 2016, 162, 1074-1088. [CrossRef]

11. Espe, E.; Potdar, V.; Chang, J. Prosumer Communities and Relationships in Smart Grids: A Literature Review, Evolution and Future Directions. Energies 2018, 11, 2528. [CrossRef]

12. Ferrari, L.; Esposito, F.; Becciani, M.; Ferrara, G.; Magnani, S.; Andreini, M.; Bellissima, A.; Cantù, M.; Petretto, G.; Pentolini, M. Development of an optimization algorithm for the energy management of an industrial Smart User. Appl. Energy 2017, 208, 1468-1486. [CrossRef]

13. Bianchi, M.; Branchini, L.; De Pascale, A.; Peretto, A. Application of environmental performance assessment of CHP systems with local and global approaches. Appl. Energy 2014, 130, 774-782. [CrossRef]

14. Barbieri, E.S.; Spina, P.R.; Venturini, M. Analysis of innovative micro-CHP systems to meet household energy demands. Appl. Energy 2012, 97, 723-733. [CrossRef]

15. Raine, R.D.; Finney, K.N.; Swithenbank, J. Optimisation of combined heat and power production for buildings using heat storage. Energy Convers. Manag. 2014, 87, 164-174. [CrossRef]

16. Ghadimi, P.; Kara, S.; Kornfeld, B. The optimal selection of on-site CHP systems through integrated sizing and operational strategy. Appl. Energy 2014, 126, 38-46. [CrossRef]

17. Buoro, D.; Pinamonti, P.; Reini, M. Optimization of a Distributed Cogeneration System with solar district heating. Appl. Energy 2014, 124, 298-308. [CrossRef]

18. De Paepe, M.; D'Herdt, P.; Mertens, D. Micro-CHP systems for residential applications. Energy Convers. Manag. 2006, 47, 3435-3446. [CrossRef]

19. Reynolds, J.; Ahmad, M.W.; Rezgui, Y.; Hippolyte, J.-L. Operational supply and demand optimisation of a multi-vector district energy system using artificial neural networks and a genetic algorithm. Appl. Energy 2019, 235, 699-713. [CrossRef]

20. Brett, D.; Fraga, E.S.; Brett, D.J. A modelling study for the integration of a PEMFC micro-CHP in domestic building services design. Appl. Energy 2018, 225, 85-97.

21. Comodi, G.; Giantomassi, A.; Severini, M.; Squartini, S.; Ferracuti, F.; Fonti, A.; Cesarini, D.N.; Morodo, M.; Polonara, F. Multi-apartment residential microgrid with electrical and thermal storage devices: Experimental analysis and simulation of energy management strategies. Appl. Energy 2015, 137, 854-866. [CrossRef]

22. Orehounig, K.; Evins, R.; Dorer, V. Integration of decentralized energy systems in neighbourhoods using the energy hub approach. Appl. Energy 2015, 154, 277-289. [CrossRef]

23. McKenna, R.; Merkel, E.; Fichtner, W. Energy autonomy in residential buildings: A techno-economic model-based analysis of the scale effects. Appl. Energy 2017, 189, 800-815. [CrossRef]

24. Zia, M.F.; Elbouchikhi, E.; Benbouzid, M. Microgrids energy management systems: A critical review on methods, solutions, and prospects. Appl. Energy 2018, 222, 1033-1055. [CrossRef]

25. Shayeghi, H.; Shahryari, E.; Moradzadeh, M.; Siano, P. A Survey on Microgrid Energy Management Considering Flexible Energy Sources. Energies 2019, 12, 2156. [CrossRef]

26. Dehghanpour, K.; Colson, C.; Nehrir, H. A Survey on Smart Agent-Based Microgrids for Resilient/Self-Healing Grids. Energies 2017, 10, 620. [CrossRef] 
27. Ghiani, E.; Serpi, A.; Pilloni, V.; Sias, G.; Simone, M.; Marcialis, G.L.; Armano, G.; Pegoraro, P.A. A Multidisciplinary Approach for the Development of Smart Distribution Networks. Energies 2018, 11, 2530. [CrossRef]

28. Georgilakis, P.S. Review of Computational Intelligence Methods for Local Energy Markets at the Power Distribution Level to Facilitate the Integration of Distributed Energy Resources: State-of-the-art and Future Research. Energies 2020, 13, 186. [CrossRef]

29. Entchev, E.; Yang, L.; Ghorab, M.; Rosato, A.; Sibilio, S. Energy, economic and environmental performance simulation of a hybrid renewable microgeneration system with neural network predictive control. Alex. Eng. J. 2018, 57, 455-473. [CrossRef]

30. Roy, K.; Mandal, K.K.; Mandal, A.C.; Patra, S.N. Analysis of energy management in micro-grid-A hybrid BFOA and ANN approach. Renew. Sustain. Energy Rev. 2018, 82, 4296-4308. [CrossRef]

31. Seo, B.; Yoon, Y.; Mun, J.; Cho, S. Application of Artificial Neural Network for the Optimum Control of HVAC Systems in Double-Skinned Office Buildings. Energies 2019, 12, 4754. [CrossRef]

32. Wang, H.; Wang, T.; Xie, X.; Ling, Z.; Gao, G.; Dong, X. Optimal Capacity Configuration of a Hybrid Energy Storage System for an Isolated Microgrid Using Quantum-Behaved Particle Swarm Optimization. Energies 2018, 11, 454. [CrossRef]

33. Wu, T.; Shi, X.; Liao, L.; Zhou, C.; Zhou, H.; Su, Y. A Capacity Configuration Control Strategy to Alleviate Power Fluctuation of Hybrid Energy Storage System Based on Improved Particle Swarm Optimization. Energies 2019, 12, 642. [CrossRef]

34. Collazos, A.; Maréchal, F.; Gahler, C. Predictive optimal management method for the control of polygeneration systems. Comput. Chem. Eng. 2009, 33, 1584-1592. [CrossRef]

35. Wille-Haussmann, B.; Erge, T.; Wittwer, C. Decentralized optimization of cogeneration in virtual power plants. Solar Energy 2010, 84, 604-611. [CrossRef]

36. Ren, H.; Gao, W. A MILP model for integrated plan and evaluation of distributed energy systems. Appl. Energy 2010, 87, 1001-1014. [CrossRef]

37. Steen, D.; Stadler, M.; Cardoso, G.; Groissböck, M.; Deforest, N.; Marnay, C. Modeling of thermal storage systems in MILP distributed energy resource models. Appl. Energy 2015, 137, 782-792. [CrossRef]

38. Wouters, C.; Fraga, E.S.; James, A. An energy integrated, multi-microgrid, MILP (mixed-integer linear programming) approach for residential distributed energy system planning-A South Australian case-study. Energy 2015, 85, 30-44. [CrossRef]

39. Ford, R.; Pritoni, M.; Sanguinetti, A.; Karlin, B. Categories and functionality of smart home technology for energy management. Build. Environ. 2017, 123, 543-554. [CrossRef]

40. Rafique, M.K.; Haider, Z.M.; Mehmood, K.K.; Zaman, M.S.U.; Irfan, M.; Khan, S.U.; Kim, C.-H. Optimal Scheduling of Hybrid Energy Resources for a Smart Home. Energies 2018, 11, 3201. [CrossRef]

41. Sanguinetti, A.; Karlin, B.; Ford, R.; Salmon, K.; Dombrovski, K. What's energy management got to do with it? Exploring the role of energy management in the smart home adoption process. Energy Effic. 2018, 11, 1897-1911. [CrossRef]

42. Allegrini, J.; Orehounig, K.; Mavromatidis, G.; Ruesch, F.; Dorer, V.; Evins, R. A review of modelling approaches and tools for the simulation of district-scale energy systems. Renew. Sustain. Energy Rev. 2015, 52, 1391-1404. [CrossRef]

43. Bellman, R. Dynamic Programming; University Press: Princeton, NJ, USA, 1957.

44. Yu, S.; Gao, S.; Sun, H. A dynamic programming model for environmental investment decision-making in coal mining. Appl. Energy 2016, 166, 273-281. [CrossRef]

45. Seijo, S.; Del Campo, I.; Echanobe, J.; García-Sedano, J. Modeling and multi-objective optimization of a complex CHP process. Appl. Energy 2016, 161, 309-319. [CrossRef]

46. Chen, X.; Hewitt, N.; Li, Z.; Wu, Q.; Yuan, X.; Roskilly, T. Dynamic programming for optimal operation of a biofuel micro CHP-HES system. Appl. Energy 2017, 208, 132-141. [CrossRef]

47. Berrueta, A.; Heck, M.; Jantsch, M.; Ursúa, A.; Sanchis, P. Combined dynamic programming and region-elimination technique algorithm for optimal sizing and management of lithium-ion batteries for photovoltaic plants. Appl. Energy 2018, 228, 1-11. [CrossRef]

48. Gambarotta, A.; Morini, M.; Pompini, N.; Spina, P.R. Optimization of Load Allocation Strategy of a Multi-source Energy System by Means of Dynamic Programming. Energy Procedia 2015, 81, 30-39. [CrossRef] 
49. Rist, J.F.; Dias, M.F.; Palman, M.; Zelazo, D.; Cukurel, B. Economic dispatch of a single micro-gas turbine under CHP operation. Appl. Energy 2017, 200, 1-18. [CrossRef]

50. Alahaivala, A.; Heß, T.; Cao, S.; Lehtonen, M. Analyzing the optimal coordination of a residential micro-CHP system with a power sink. Appl. Energy 2015, 149, 326-337. [CrossRef]

51. Bahlawan, H.; Morini, M.; Pinelli, M.; Spina, P.R. Dynamic programming based methodology for the optimization of the sizing and operation of hybrid energy plants. Appl. Therm. Eng. 2019, 160, 113967. [CrossRef]

52. Cattozzo, M.; Manservigi, L.; Spina, P.R.; Venturini, M. Minimization of the primary energy consumption of residential users connected by means of an energy grid. In Proceedings of the AIP Conference Proceedings, Modena, Italy, 11-13 September 2019; 2019; Volume 2191, p. 020041. [CrossRef]

53. Marano, V.; Rizzo, G.; Tiano, F.A. Application of dynamic programming to the optimal management of a hybrid power plant with wind turbines, photovoltaic panels and compressed air energy storage. Appl. Energy 2012, 97, 849-859. [CrossRef]

54. Sundstrom, O.; Guzzella, L. A generic dynamic programming Matlab function. In Proceedings of the 18th IEEE International Conference on Control Applications Part of 2009 IEEE Multi-Conference on Systems and Control, Saint Petersburg, Russia, 8-10 July 2009.

55. Available online: http://www.idsc.ethz.ch/research-guzzella-onder/downloads.html (accessed on 21 January 2019).

56. Macchi, E.; Campanari, S.; Silva, P. La Microcogenerazione a Gas Naturale; Polipress: Milano, Italy, 2006.

57. Ippolito, F.; Venturini, M. Development of a Simulation Model of Transient Operation of Micro-Combined Heat and Power Systems in a Microgrid. J. Eng. Gas Turbines Power 2017, 140, 032001. [CrossRef]

58. Ziviani, D.; Beyene, A.; Venturini, M. Advances and challenges in ORC systems modeling for low grade thermal energy recovery. Appl. Energy 2014, 121, 79-95. [CrossRef]

59. Adam, A.; Fraga, E.S.; Brett, D. Options for residential building services design using fuel cell based micro-CHP and the potential for heat integration. Appl. Energy 2015, 138, 685-694. [CrossRef]

60. Murugan, S.; Horák, B. A review of micro combined heat and power systems for residential applications. Renew. Sustain. Energy Rev. 2016, 64, 144-162. [CrossRef]

61. Xiong, L.; Nour, M. Nour Techno-Economic Analysis of a Residential PV-Storage Model in a Distribution Network. Energies 2019, 12, 3062. [CrossRef]

62. Ren, H.; Gao, W.; Ruan, Y. Optimal sizing for residential CHP system. Appl. Therm. Eng. 2008, 28, 514-523. [CrossRef]

63. COMMISSION DELEGATED REGULATION (EU) 2015/2402 of 12 October 2015, Official Journal of the European Union. Available online: https://eur-lex.europa.eu (accessed on 3 February 2020).

64. Decreto Ministeriale 5 Settembre 2011-Regime di Sostegno per la Cogenerazione ad alto Rendimento; 2011. Available online: https://www.mise.gov.it/images/stories/normativa/DM-5-SETTEMBRE2011.pdf (accessed on 3 February 2020). (In Italian)

65. Available online: https://www.e-education.psu.edu/eme812/node/738 (accessed on 3 February 2020).

66. Facci, A.L.; Ubertini, S. Analysis of a fuel cell combined heat and power plant under realistic smart management scenarios. Appl. Energy 2018, 216, 60-72. [CrossRef]

67. Telaretti, E.; Ippolito, M.G.; Dusonchet, L. A Simple Operating Strategy of Small-Scale Battery Energy Storages for Energy Arbitrage under Dynamic Pricing Tariffs. Energies 2015, 9, 12. [CrossRef]

68. Darrow, K.; Tidball, R.; Wang, J.; Hampson, A. Catalog of CHP Technologies, U.S. Environmental Protection Agency Combined Heat and Power Partnership; 2017. Available online: https://www.epa.gov/sites/production/ files/2015-07/documents/catalog_of_chp_technologies.pdf (accessed on 3 March 2020).

69. Mapping and Analyses of the Current and Future (2020-2030) Heating/Cooling Fuel Deployment (Fossil/Renewables); European Commission Directorate-General for Energy Directorate C; 2-New Energy Technologies, Innovation and Clean Coal. 2016. Available online: https://ec.europa.eu/energy/sites/ener/files/documents/mapping-hcexcecutivesummary.pdf (accessed on 3 March 2020).

70. Sarbu, I.; Sebarchievici, C. A Comprehensive Review of Thermal Energy Storage. Sustainability 2018, 10, 191. [CrossRef]

71. Available online: https://www.metrotherm.dk/en (accessed on 3 March 2020).

72. Ribberink, H.; Entchev, E. Exploring the potential synergy between micro-cogeneration and electric vehicle charging. Appl. Therm. Eng. 2014, 71, 677-685. [CrossRef] 
73. Angrisani, G.; Canelli, M.; Roselli, C.; Sasso, M. Integration between electric vehicle charging and micro-cogeneration system. Energy Convers. Manag. 2015, 98, 115-126. [CrossRef]

74. García-Villalobos, J.; Zamora, I.; Martin, J.I.S.; Asensio, F.J.; Aperribay, V. Plug-in electric vehicles in electric distribution networks: A review of smart charging approaches. Renew. Sustain. Energy Rev. 2014, 38, 717-731. [CrossRef] 